\begin{tabular}{|c|c|c|}
\hline \multirow{2}{*}{$\begin{array}{r}\text { Case Reports in } \\
\text { Gastroenterology }\end{array}$} & \multicolumn{2}{|c|}{ Case Rep Gastroenterol 2018;12:390-395 } \\
\hline & $\begin{array}{l}\text { DOI: } 10.1159 / 000490659 \\
\text { Published online: August 21, } 2018\end{array}$ & $\begin{array}{l}\text { (c) } 2018 \text { The Author(s) } \\
\text { Published by S. Karger AG, Basel } \\
\text { www.karger.com/crg }\end{array}$ \\
\hline & $\begin{array}{l}\text { This article is licensed under the } \\
\text { International License (CC BY-NC) } \\
\text { Usage and distribution for commer }\end{array}$ & $\begin{array}{l}\text { nons Attribution-NonCommercial } 4.0 \\
\text { ger.com/Services/OpenAccessLicense). } \\
\text { guires written permission. }\end{array}$ \\
\hline
\end{tabular}

\title{
Adenocarcinoma Arising from Perianal Fistulizing Crohn's Disease
}

\author{
Rosario Fornaro ${ }^{a}$ Marco Frascio $^{a}$ Michela Caratto $^{a}$ Elisa Caratto ${ }^{a}$ \\ Rita Bianchi $^{\mathrm{b}} \quad$ Andrea Razzore $^{\mathrm{a}} \quad$ Giuseppe Caristo $^{\mathrm{a}} \quad$ Camilla Sticchi $^{\mathrm{c}}$ \\ Marco Casaccia ${ }^{a}$ \\ aDepartment of Surgery, Polyclinic San Martino Hospital, University of Genoa,

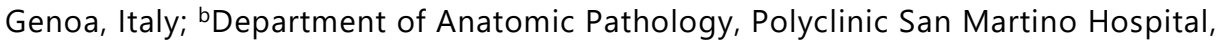 \\ University of Genoa, Genoa, Italy; ${ }^{\mathrm{C}} \mathrm{ALISA}$ - Sistema Sanitario Regione Liguria, Area \\ Sanitaria Prevenzione, Epidemiologia, Genoa, Italy
}

\section{Keywords}

Crohn's disease $\cdot$ Perianal fistula $\cdot$ Adenocarcinoma

\begin{abstract}
Perianal fistula is a very debilitating event and a cause of morbidity in patients with Crohn's disease (CD). Its malignant transformation is very rare with an incidence of around $0.004-0.7 \%$. Presence of disease in the colon and rectum is the major risk factor for the development of a perianal fistula. In this report we show a case of adenocarcinoma arising from a perianal fistulizing CD. This type of tumor is highly aggressive, difficult to diagnose, and has a rather poor prognosis. The different neoplastic transformations and the different types of tumors that may appear in patients with $C D$, especially at the colorectal level or at the level of an eventual anastomosis, are to date well documented and described in the literature, while there is a lack of information and of treated cases concerning the occurrence of cancer at the level of a fistula. Due to the rarity of cases, we tried to identify the most frequent and important risk factors: sex, duration of disease, age at diagnosis, and the history of the fistula.
\end{abstract}

(c) 2018 The Author(s)

Published by S. Karger AG, Basel 


\section{Introduction}

Perianal fistula is common in patients with Crohn's disease (CD), with an estimated cumulative incidence of around $30-50 \%[1,2]$. Presence of disease in the colon and rectum is the major risk factor for the development of a perianal fistula [1]. The location of the disease, age at diagnosis, type of fistula, presence or absence of abscesses, and intestinal stenosis can affect the natural history of perianal CD. Perianal fistula is associated with pain, perianal swelling, and fever in case of perianal abscess and drainage of pus, feces, or blood from the fistula. Perianal CD treatment requires a combined approach between the clinician and the surgeon and should aim at resolving and preventing septic complications, treating the fistula with an improvement in the patient's quality of life and healing the fistula itself [3]. The onset of cancers from the fistula itself is a rather rare occurrence (around 0.004-0.7\%), especially in the case of adenocarcinoma [1].

\section{Case Report}

In February 2018, a 60-year-old woman with fistulizing CD for about 40 years came to our attention because of the appearance of worsening asthenia and abdominal pain. Her past medical history was positive for left colon resection with colostomy packaged about 20 years before, for ileocecectomy carried out in 2005 due to adhesion syndrome, and for fistulotomy in 2015 because of multiple rectovaginal and rectocutaneous fistula. The patient was considerably underweight ( $45 \mathrm{~kg}$ ). Objective examination of heart, chest, and hypochondriac organs was negative. The abdomen was flat and manageable, painless with torpid peristalsis. The ostomy appeared retracted and stenotic into the left site were not evaluable. At the perianal level, it was possible to appreciate multiple fistulous ostia with presence of minimal granulation tissue and abundant mucous-purulent secretions that also involved the labia majora. The perineum appeared completely destructured. The patient regularly took prednisone $(5 \mathrm{mg})$, lansoprazole (30 mg), and ciprofloxacin (500 mg). She had suspended mesalazine (800 mg) because of the appearance of a probably drug-related skin rash. Abdominal CT, carried out in order to restage the disease and evaluate perianal involvement, showed, on the lateral and posterolateral right side of the anal canal, a $21 \times 21 \mathrm{~mm}$ hyperdense thickening also extending to the levator ani muscle of the omolateral side, probably representing an abscess. In addition, at the anal level there was a fluid and gaseous collection of $27 \times 81 \mathrm{~mm}$, extending also to the vagina and major labia. MRI of the lower abdomen showed two subtle striae hyperintense on T2-weighted sequences fat-sat, localized posteriorly and in the left subsphincter region; these findings were evaluated as fistulas. After evaluating the objective exam as well as hematochemical and instrumental examinations, we proposed to the patient, in agreement with our gastroenterologists, a multidisciplinary therapeutic program that included initial surgical drainage of the perianal fistulas with the Miles technique and repackaging of the retracted ostomy, followed by medical therapy. The surgery involved two stages, one abdominal and the other perineal. The surgeon accessed the abdominal cavity through a xipho-pubic incision. After viscerolysis the sigmoid ostomy was isolated and dissected. We identified the rectosigmoid stump that was isolated up to the rectum wings. A left ovarosalpingectomy was necessary due to adherences which evolved in an abscess probably coming from the rectal stump. Then $10 \mathrm{~cm}$ of sigma were resected after mobilization of the splenic flexure which involved a necessary splenectomy. The remaining colon was mobilized up to half of the transverse colon. The ostomy was packaged on the distal transverse side at the level of the right iliac fossa 


\section{Case Reports in Gastroenterology}

Case Rep Gastroenterol 2018;12:390-395

DOI: $10.1159 / 000490659$

c) 2018 The Author(s). Published by S. Karger AG, Basel www.karger.com/crg

Fornaro et al.: Adenocarcinoma Arising from Perianal Fistulizing Crohn's Disease

because of the presence of multiple abscesses and cutaneous ulcers at the site of the previous ostomy. The reconstruction of the pelvic floor and the excision of the preexisting ostomy were carried out with biopsy of the peristomal cutaneous lesion. Two drainages were applied: an upper one in the splenic loggia and a lower one in the neo-Douglas. After repeated washings and hemostasis control, the surgical breaches were synthesized and the ostomy was opened. Later we performed an excision of the anorectal canal as the perineum was deconstructed. We proceeded to the partial closure of the ischiorectal excavation with placement of a perineal drainage. The removed material was sent to the anatomopathologists (Fig. 1). The postoperative course was regular. The final histological examination showed normal findings as concerned the ovary, the spleen, the ostomy, the colon, and the parastomal skin, while it showed adenocarcinoma of the large intestine as regards the sigmarectoanal canal specimen. This was an adenocarcinoma arising from flat low-grade and high-grade dysplasia, infiltrating the wall up to the subserous adipose tissue (pT3) with a maximum extension of $3 \mathrm{~mm}$ from the outer limit of the muscle membrane in the perivisceral adipose tissue. The neoplasia showed infiltrative growth with abundant single cells and poor peri- and intratumoral lymphocytic infiltration. In the wall and in the adipose tissue underlying the neoplasia, numerous lymphoid aggregates and gigantocellular granulomas (compatible with $\mathrm{CD}$ ) were observed. On the serosa, bleeding as well as granulocytic and histiocytic inflammatory infiltrates could be observed to configure a picture of localized peritonitis. Neoplastic invasion of the sphincter muscle was not observed. As regards grading, the neoplasia was classified as G3 and according to Dukes' classification as B2. High-grade tumor budding was present and was evaluated with anticytokine antibodies AE1 and AE3. Vascular invasion was not documented while perineural invasion was present and widespread. The expression of the protein product encoded by DNA repair genes was also evaluated: MSH- 6 and PMS-2 were conserved, while CDX-2 had a partial loss of nuclear positivity (Fig. 2). The eight isolated pericolic lymph nodes were disease-free. The proximal margin and the distal margin sampled on the operating piece were disease-free. The radial margin showed a distance of $1 \mathrm{~mm}$ from the neoplasm. After evaluating the new clinical situation, we contacted our oncologist for postoperative staging of the neoplasm and evaluation of a possible antitumor therapy. In consideration of stage II of the disease, the most appropriate therapy involved postoperative radiotherapy (45 Gy) associated with capecitabine chemotherapy $1,650 \mathrm{mg} / \mathrm{m}^{2} /$ day within 2.5 months after surgery. The patient refused any kind of treatment and only accepted perineum dressings.

\section{Discussion}

$\mathrm{CD}$ is an inflammatory bowel disease characterized by a chronic and transmural inflammation that can affect the entire gastrointestinal tract, from the mouth to the anus. In CD one of the most frequent complications are fistulas, which can arise along the entire gastrointestinal tract, although in most cases they are perianal (54\%), enteric (24\%), or rectovaginal (9\%). One-third of CD patients will have recurrent fistulas that are difficult to manage for both the clinician and the surgeon [4-6]. The chronic inflammatory process that characterizes this disease exposes $\mathrm{CD}$ patients to an increased risk of cancer [7]: they have a risk two to three times higher than the general population [4-6]. The different neoplastic transformations and the different types of tumors that may appear in patients with CD, especially at the colorectal level or at the level of an eventual anastomosis, are to date well documented and described in the literature, while there is a lack of information and of treated cases concerning the occurrence of cancer at the level of a fistula (the carcinoma rate is $<1 \%$ ). 
Due to the rarity of the cases, we tried to identify the most frequent and important risk factors: (1) Sex. The female sex is much more predisposed; $57 \%$ of the cases treated in the literature deal with women, with an average age of around 57. (2) Duration of the disease and age at diagnosis. Long-term disease and young age at diagnosis are predisposing factors that unite most of these patients. (3) History of the fistula. The risk of neoplastic transformation is directly proportional to the time for which the fistula remains in situ. After 7-10 years the patient should be controlled more regularly.

In most cases, histologically it is an adenocarcinoma, but squamous cell carcinomas are not uncommon and are also more responsive to radiotherapy [8]. Many times the diagnosis is made accidentally, during normal follow-up, because the patient is asymptomatic or the signs and symptoms are attributed to the underlying perianal disease. The available diagnostic techniques (endoanal US, CT, MRI, PET) in most cases cannot distinguish between benign inflammatory lesions (typical of inflammatory bowel disease) and malignant lesions [1, 9]. For all these reasons, the diagnosis is almost always made late when the disease is already in an advanced state [1, 9]. As reported by Iesalnieks et al. [9], 95\% of patients have a T3/T4 stage at the time of diagnosis, and $50 \%$ of these already have positivity (N1) of inguinal lymph nodes, while $10 \%$ already have distant metastases. The prognosis is not good at all, especially if there is involvement of locoregional lymph nodes. Elective therapy is surgical followed by postoperative radiotherapy and chemotherapy. An abdominoperineal resection according to Miles is performed with a very high risk of recurrence. In patients with positive locoregional lymph nodes, the risk of relapse is around 16.6 months [9]. Five-year survival is very low $(<26 \%)$.

In conclusion, adenocarcinoma originating from a perianal fistula is a highly aggressive tumor, difficult to diagnose and with a rather poor prognosis. Although it has been established that the follow-up of such patients, carried out to control their inflammatory bowel disease, especially using instrumental examinations, is not very useful for diagnosing adenocarcinoma, some authors have stressed the importance of monitoring patients with a long history of CD associated with perianal fistula, because, even if very low, the possibility of a neoplastic transformation exists.

\section{Statement of Ethics}

The authors have no ethical conflicts to disclose.

\section{Disclosure Statement}

The authors have nothing to declare.

\section{References}

1 Baars JE, Kuipers EJ, Dijkstra G, Hommes DW, de Jong DJ, Stokkers PC, et al.; Initiative for Crohn and Colitis. Malignant transformation of perianal and enterocutaneous fistulas is rare: results of 17 years of follow-up from The Netherlands. Scand J Gastroenterol. 2011 Mar;46(3):319-25.

2 Hughes LE. Surgical pathology and management of anorectal Crohn's disease. J R Soc Med. 1978 Sep;71(9):644-51. 
Fornaro et al.: Adenocarcinoma Arising from Perianal Fistulizing Crohn's Disease

3 Gecse KB, Bemelman W, Kamm MA, Stoker J, Khanna R, Ng SC, et al.; World Gastroenterology Organization, International Organisation for Inflammatory Bowel Diseases IOIBD, European Society of Coloproctology and Robarts Clinical Trials; World Gastroenterology Organization International Organisation for Inflammatory Bowel Diseases IOIBD European Society of Coloproctology and Robarts Clinical Trials. A global consensus on the classification, diagnosis and multidisciplinary treatment of perianal fistulising Crohn's disease. Gut. 2014 Sep;63(9):1381-92.

4 Fornaro R, Caratto M, Caratto E, Caristo G, Fornaro F, Giovinazzo D, et al. Colorectal cancer in Patients with Inflammatory Bowel Disease: the need for a real surveillance program. Clin Colorectal Cancer. 2016 Sep;15(3):204-12.

5 Fornaro R, Caratto E, Caratto M, Fornaro F, Caristo G, Frascio M, et al. Post-operative recurrence in Crohn's disease. Critical analysis of potential risk factors. An update. Surgeon. 2015 Dec;13(6):330-47.

6 Fornaro R, Frascio M, Den egri A, Stabilini C, Impenatore M, Mandolfino F, et al. [Crohn's disease and cancer]. Ann Ital Chir. 2009 Mar-Apr;80(2):119-25.

7 Traube J, Simpson S, Riddell RH, Levin B, Kirsner JB. Crohn's disease and adenocarcinoma of the bowel. Dig Dis Sci. 1980 Dec;25(12):939-44.

8 Consorti F, Lorenzotti A, Midiri G, Di Paola M. Prognostic significance of mucinous carcinoma of colon and rectum: a prospective case-control study. J Surg Oncol. 2000 Feb;73(2):70-4.

9 Iesalnieks I, Gaertner WB, Glass H, Strauch U, Hipp M, Agha A, et al. Fistula-associated anal adenocarcinoma in Crohn's disease. Inflamm Bowel Dis. 2010 Oct;16(10):1643-8.
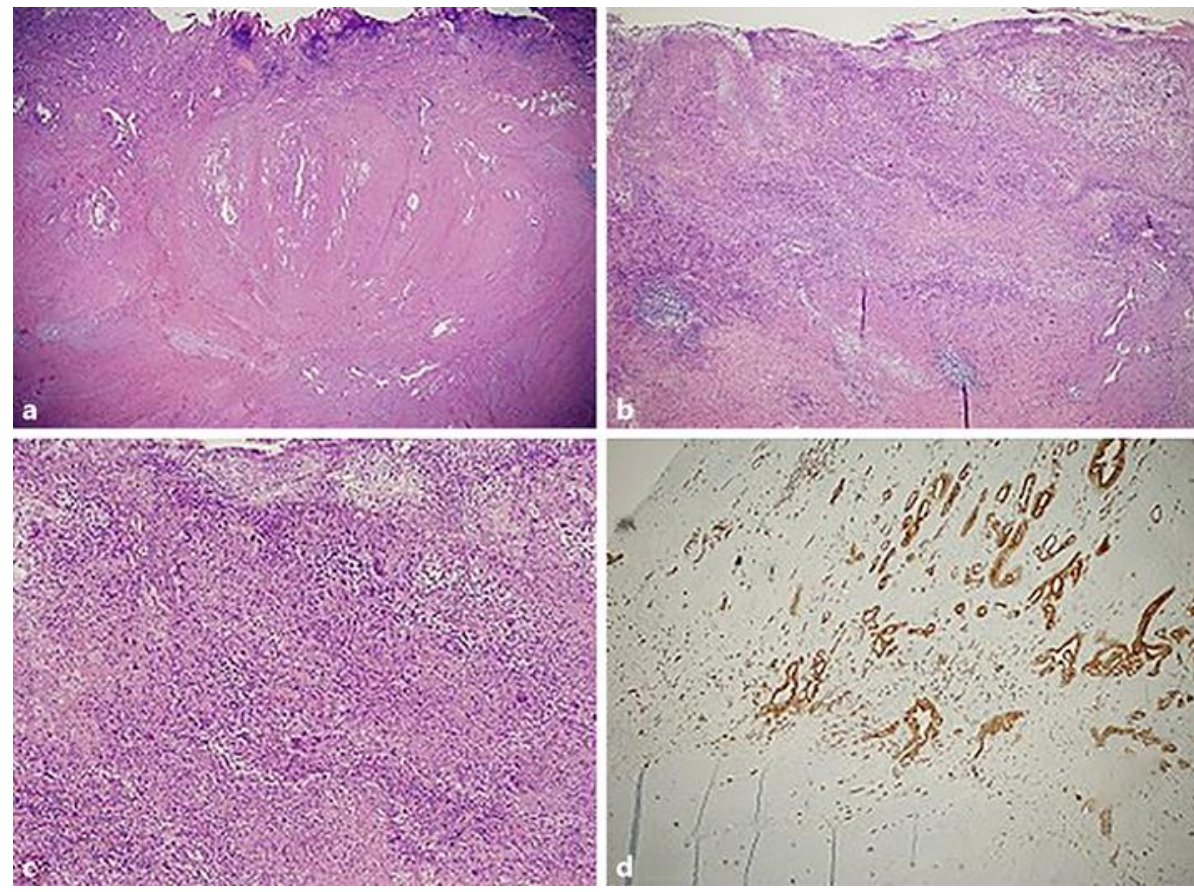

Fig. 1. a Lower magnification showing diffuse infiltration of a scarcely differentiated tumor in the muscular walls of the intestine and the dysplasia of the mucosa from which it derives. Hematoxylin and eosin, $\times 200$. b Together with the neoplasia an extensive inflammatory status can be observed in the intestinal wall, with pseudofollicular lymphocytic aggregates and multiple granulomas. Hematoxylin and eosin, $\times 400$. c At higher magnification, multiple granulomas with multinucleated cells can be observed. Hematoxylin and eosin, $\times 1,000$. $\mathbf{d}$ Immunohistochemical reaction for cytokeratin AE1-AE3, an epithelial marker, showed a single cell infiltration of the neoplasia in the intestinal wall. Cytokeratin AE1-AE3, $\times 400$. 


\section{Case Reports in Gastroenterology}

\begin{tabular}{l|l}
\hline Case Rep Gastroenterol 2018;12:390-395 \\
\hline DOI: 10.1159/000490659 & $\begin{array}{l}\text { c 2018 The Author(s). Published by S. Karger AG, Basel } \\
\text { www.karger.com/crg }\end{array}$ \\
\hline
\end{tabular}

Fornaro et al.: Adenocarcinoma Arising from Perianal Fistulizing Crohn's Disease
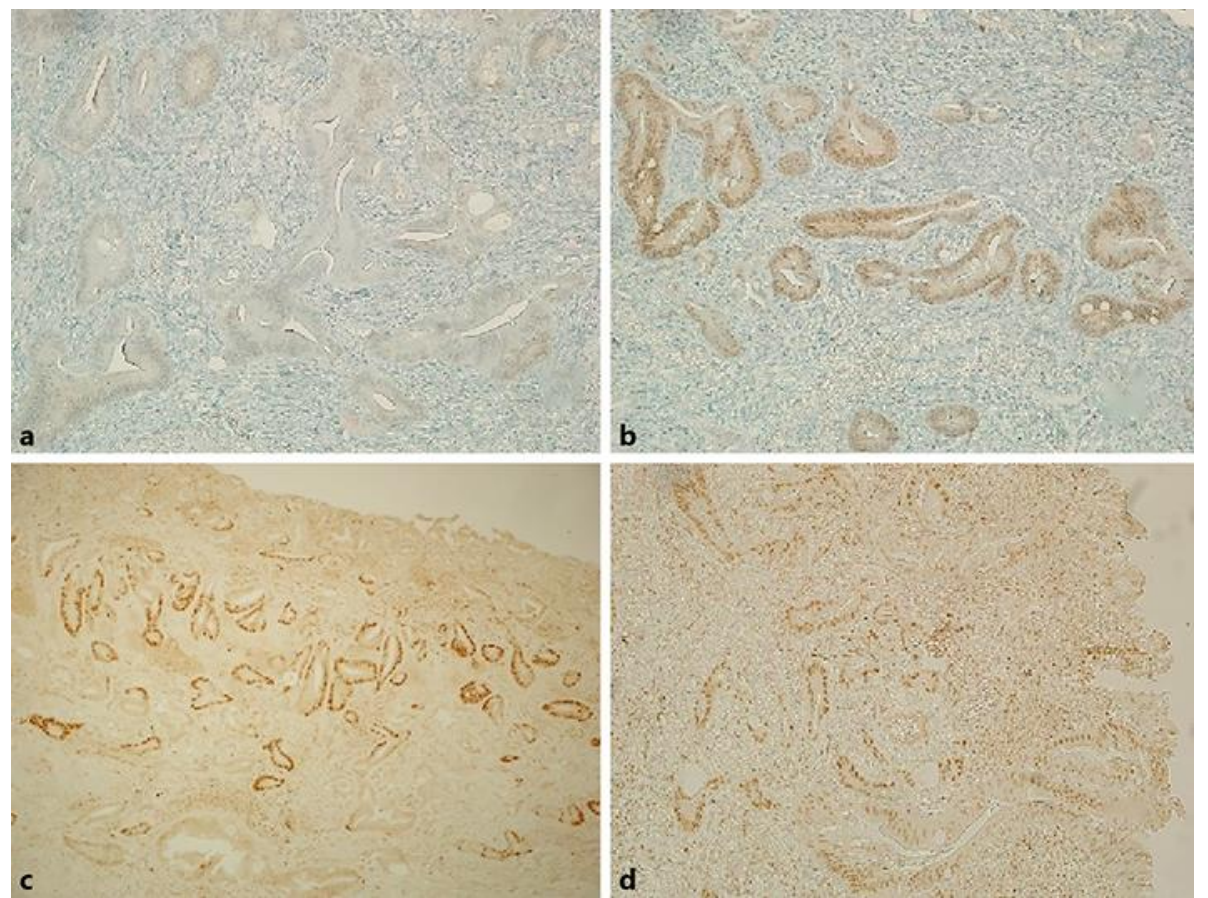

Fig. 2. a Nuclear expression of CDX-2 in a portion of adenocarcinomatous glands. CDX-2, $\times 200$. $\mathbf{b}$ Another part of the same lesion showed loss of CDX-2 expression. CDX-2, $\times 200$. c, d Expression of microsatellites MSH-6 (c) and PMS-2 (d) was maintained by neoplastic glands. c MSH-6, ×100. d PMS-2, ×200. 